\title{
Atrial Fibrillation After Coronary Artery Bypass Surgery: Risk Factors
}

Etik Kurul Onayı: S.B. Dr. Siyami Ersek Göğüs, Kalp, Damar Cerrahisi Eğitim ve Araştırma Hastanesi Yerel Etik Kurul onayı alınmıştır (17.01.2008-14/5).

Çıkar çatışması: Cııkar çatışması olmadığını bildirmișlerdir.

Finansal destek: Bu çalışma, herhangi bir fon tarafından desteklenmemiștir.

Hasta onamı: Hasta ve hasta yakınlarından aydınlatıımıs onam alınmıştı.
Ethics Committee: S. B. Dr. Siyami Ersek Chest, Cardiovascular Surgery Training and Research Hospital Local Ethics Committee approval was obtained (17.01.2008-14/5). Conflict of interest: The authors reported no conflict of interest. Funding: This work was not supported by any funding. Informed consent: Informed consent was obtained from the patient and relatives.

Cite as: Karakaş O, Yurtseven N, Savaşkan D. Koroner arter baypas cerrahisi sonrası atriyal fibrilasyon: Risk faktörleri. GKDA Derg. 2020;26(2):71-9.

\section{öz}

Amaç: Koroner arter baypas greft (KABG) cerrahisi sonrası görülen en sık ritm bozukluğu olan Atriyal Fibrilasyonda (AF) risk faktörlerini belirlemek ve C-Reaktif Protein (CRP) ile AF arasında bir korelasyon olup olmadığını göstermektir.

Yöntem: Koroner arter cerrahisi yapılacak 250 hasta prospektif olarak çalışmaya alındı. Tüm hastaların demografik verileri, peroperatif ve postoperatif değişkenleri ve postoperatif 6.güne dek günlük CRP ve AF takipleri ile, AF olanların tedavi protokolleri kaydedildi.

Bulgular: Takip edilen hastaların 43'ünde $(\% 17,2)$ AF tespit edildi. Multivariate analizde, ileri yass, hipertansiyon (HT) ve preoperatif kalsiyum kanal blokeri kullanma ile AF arasında anlamlı bir ilişki olduğu saptandı ( $p<0.05)$. CRP değerleri postoperatif 2. günde en yüksek değere ulaştı. AF bu dönemde 14 hastada görülmüş (\%5.6) olmakla birlikte, CRP yüksekliği ile AF gelişimi arasında bir ilişki tespit edilemedi ( $p>0.05)$. AF gelişen hastaların yoğun bakım ve hastanede kalışsürelerinin istatistiksel olarak anlamlı uzun olduğu gözlendi ( $p<0.05)$.

Sonuç: $A B G$ operasyonu geçiren ileri yaştaki, hipertansif, preoperatif kalsiyum kanal blokeri kullanan hastalarda, AF gelişme riskinin daha fazla olduğu ve AF tespit edilen hastaların yoğun bakım ve hastanede kalışsürelerinin daha uzun olduğu tespit edilmiş ve AF ile CRP arasında bir korelasyon bulunamamıştır.

Anahtar kelimeler: atrial fibrilasyon, koroner cerrahisi, risk faktörleri

\section{ABSTRACT}

Objective: The aim of this study was to determine the risk factors in atrial fibrillation (AF), which is the most common rhythm disorder observed after coronary artery bypass graft (CABG) surgery, and to show whether there is a correlation between C-reactive protein (CRP) and AF.

Methods: A total of 250 patients who would undergo coronary artery surgery were retrospectively included in the study. Demographic data, peroperative and postoperative variables of all patients, daily CRP and AF follow-ups until the 6th postoperative day and treatment protocols of AF patients were recorded.

Results: AF was detected in 43 (17.2\%) of the patients who were followed up. It was found that there was a statistically significant relationship in the multivariate analysis between advanced age, hypertension (HT) and use of preoperative calcium channel blocker and AF ( $p<0.05)$. CRP values reached the highest value on the 2 nd postoperative day. Although AF was seen in 14 patients (5.6\%) in this period, no relation was found between increased CRP levels and the development of AF ( $p>0.05)$. It was observed that the length of intensive care and hospital stay of patients with $A F$ was statistically significantly longer $(p<0.05)$.

Conclusion: It was found that older hypertensive patients who preoperatively used calcium channel blocker had a higher risk of developing AF. Duration of ICU and hospital stay was longer, and no correlation was found between AF and CRP.
Received: 23 May 2020

Accepted: 5 June 2020 Publication date: 30 June 2020

Nurgül Yurtseven S.B.Ü. Dr. Siyami Ersek Göğüs Kalp ve Damar Cerrahïsī Anestezi ve Reanimasyon Kliniği, İstanbul - Türkiye

nurgulyurtseven@hotmail.com ORCID: 0000-0001-9991-2859

O. Karakaş 0000-0002-8794-6100 S.B.Ü. Yüksek ihtisas Eğitim ve Araştrma Hastanesi Bursa - Türkiye

D. Savaşkan 0000-0001-5453-1657 S.B.Ü. Dr. Siyami Ersek Gögüus Kalp ve Damar Cerrahïsī Anestezi ve Reanimasyon Kliniği Istanbul - Türkiye

${ }^{\S}$ Bu çalışma, 2008 yılında Oya Karakaş tarafindan yapılmış olan tezden üretilmiştir. 


\section{GiRiş ve AMAÇ}

AF, açık kalp cerrahisi sonrası \%10-50 sıklıkla en sık görülen komplikasyonlardan biridir ${ }^{[1-3]}$. Operasyondan sonra 48-72 saat içinde pik yapar ve hastanede kalış süresini ortalama 2-5 gün uzatırken, inme riskini ise 2-3 kat arttırır ${ }^{[4,5]}$.

Bu komplikasyonun nedenleri ve patogenezi çok faktörlüdür. Bunlar arasında; kanülasyon sonrası atriyal travma, basınç veya volüm ile akut atriyal genişleme, postoperatif elektrolit bozukluğu, perikardit, sağ koroner artere (RCA) greft uygulaması, kalp kapak hastalığı olması, postoperatif sempatik tonüs artışı, beta-bloker ilaçların postoperatif dönemde kesilmesi ve kronik böbrek yetersizliği (KBY) öyküsü bulunmasıdır ${ }^{[6]}$. Inflamatuvar mekanizmalar ve renin angiotensin aldosteron sistemi de (RAAS), AF patogenezinde anahtar rol oynar ${ }^{[7-10]}$. Enflamasyonun bir göstergesi olan C-Reaktif proteinin (CRP) artmış koroner olay riskiyle ilişkili olduğu gösterilmiştir ${ }^{[11]}$. CRP'nin normal değerleri içindeki hafif artış bile kardiyovasküler olay riskini artırmaktadır. CRP, AF gözlenen olgularda yükselmiştir ${ }^{[12]}$.

Prospektif çalışmamızın birincil amacı koroner arter baypas cerrahisi (KABG) uygulanan hastalarda $A F$ sıklığını ve risk faktörlerini saptamak, ikincil amacı ise, bu hastalarda postoperatif CRP düzeyi ile $\mathrm{AF}$ arasında bir korelasyon olup olmadığını göstermektir.

\section{GEREÇ ve YÖNTEM}

Bu çalışmada farklı cerrahi ekipler tarafından KABG cerrahisi uygulanan ve preoperatif normal sinüs ritminde olan 250 hasta prospektif olarak incelendi. KABG cerrahisi dışında ilave operasyonlar geçiren (kapak girişimi, ventrikülotomi gibi), ve acil girişim yapılan hastalar ise hipertrodi öyküsü, preoperatif AF'si olan, karaciğer enzimleri yüksek, kronik renal yetmezliği olan, steroid veya nonsteroid antiinflamatuvar ilaç kullanan hastalar çalışma dışı bırakıldı. Hastaların peroperatif ve postoperatif değişkenleri prospektif olarak kaydedilerek AF gelişimi üzerine olan etkileri değerlendirildi.

Tüm hastalara benzer anestezi yönetimi ve cerrahi teknik uygulandı. Demografik verilere ilave olarak, fonksiyonel kapasite, hipertansiyon (HT), diyabetes mellitus (DM), kronik obstruktif akciğer hastalığı $(\mathrm{KOAH})$, kronik renal yetmezlik (KRY), periferik arter hastalığı (PAH), serebrovasküler olay (vertebrobaziler yetmezlik, inme vb.) (Karotis tıkanıklığı veya stenozu >\%50), miyokard enfarktüsü (MI), preoperatif beta-bloker, Ca++ kanal blokeri, statin, anjiotensin converting enzim ihibitör (ACE-I), digoksin kullanımı, ejeksiyon fraksiyonu (EF), sigara kullanımı, kreatinin, potasyum $\left(\mathrm{K}^{+}\right)$, magnezyum $\left(\mathrm{Mg}^{++}\right)$, CRP değerleri kaydedildi. Operasyon sonrası yoğun bakım ünitesine alınan hastalar, fraksiyone oksijen düzeyleri $\left(\mathrm{FiO}_{2}\right)$ : 0,60, solunum sayısı: 12 , PEEP: 5, PS: 15 , tidal volüm: 6-8 $\mathrm{ml} / \mathrm{kg}$ değerleri ile SIMV+PS modunda mekanik ventilatöre bağlandı ve bu değerler hastanın hemodinamik durumu ve uyanıklılığı değerlendirilerek kademeli olarak indirildi. Elektrokardiyografi (EKG), ortalama arter basıncı, kalp hızı, santral venöz basınç takibi yapıldı. Yoğun bakım süresince kan gazı kontrollerine göre gerekli elektrolit replasmanları yapıldı ve hastalar ekstubasyon kriterlerini sağladığında mekanik ventilasyon desteği sonlandırıldı. Klinik seyri normal olan hastalar, postoperatif birinci gün direnleri alınarak servise çıkarıldı.

Hastalarda AF varlığı ve CRP değerleri yoğun bakım ünitesine kabulde (TO), 1. gün (T1), 2. gün (T2), 3. gün (T3), 4. gün (T4), 5. gün (T5) ve 6. gün (T6) olmak üzere kaydedildi. Servise alınan hastalara maksimum 6 saatlik aralıklarla EKG ve kan basıncı takibi yapıldı. Postoperatif dönemde monitörden veya rutin takip sırasında aritmi saptanan veya çarpıntı şikayeti olan hastalara standart 12 derivasyonlu EKG çekildi. Hastalar AF varlığına göre iki gruba ayrıldı: Grup 1: AF saptanan hastalar, Grup 2: Kontrol.

AF saptanan hastalar elektrolit dengesizliği açısından kontrol edilerek gereği halinde replasmanı yapıldı. Tedaviye yanıt alınamayan hastalara amiadoron ve/ veya $\mathrm{Mg++}$ tedavi protokolü uygulandı. Ateş $38.5^{\circ} \mathrm{C}$ 
ve üzeri olan hastalarda lökosit takibi ve gerektiğinde yara yeri, kan ve idrar kültürleri alındı. Ayrıca operasyon sonrası inotropik ajan ve intraaortik balon pompası (IABP) kullanımı, total direnaj miktarı, K+ ve Mg++ değerleri, vücut ISısı, böbrek yetmezliği, postoperatif Mi, entübasyon süresi (saat), yoğun bakımda kalış süresi (gün) ve hastanede kalış süresi (gün) kaydedildi.

\section{İstatistiksel İncelemeler}

Çalışmada elde edilen bulgular değerlendirilirken, istatistiksel analizler için NCSS 2007\&PASS 2008 Statistical Software (Utah, USA)programı kullanıldı. Çalışma verileri değerlendirilirken tanımlayıcı istatistiksel metodların (Ortalama, Standart sapma) yanısıra iki gruba göre değerlendirmelerde student $t$ test ve Mann Whitney U test kullanıldı.

Univariate analizde anlamlı çıkan veya anlamlılığa yakın bulunan parametreler, AF üzerine etki eden risk faktörleri açısından Multivariate analizlerden Lojistik Regresyon analizi ile değerlendirildi. Niteliksel verilerin karşılaştırılmasında ise Ki-Kare testi ve Fisher's Exact Ki-Kare testi kullanıldı. Sonuçlar \% 95'lik güven aralığında ve anlamlılık $p<0.05$ düzeyinde değerlendirildi.

\section{BULGULAR}

Çalışma yaşları 26 ile 78 arasında değişen; 53’ü (\%21.2) kadın ve 197'si (\%78.8) erkek toplam 250 olgu üzerinde yapılmıştır. 250 hastanın 43'ünde $A F$ tespit edilmiş olup, görülme oranı \%17.2'dir. AF görüIen Grup 1 hastalarında yaş ortalaması 64.65 \pm 7.18 iken, Grup 2 hastalarında $57.59 \pm 9.60$ belirlenmiş ve istatistiksel olarak anlamlı bulunmuştur. Benzer şekilde HT, Grup 1 hastalarında daha sık görüldüğü tespit edilmiştir (Tablo 1, p<0,01).

Gruplar EF ölçümleri ve kreatinin değeri, NYHA sınıflamaları, PDH varlığı, SVO ve MI varlığı, sigara kullanımı, beta bloker, statin, ACE inhibitörü kullanımı ve kullanılan greft sayısı açısından benzerken Ca++ kanal blokörü kullanım oranlarının, Grup 1 hastalarında daha yüksek olduğu belirlenmiştir (Tablo 2, p<0,05).

Grupların peroperatif değişkenleri benzerken (Tablo 3), postoperatif değişkenler karşılaştırıldığında, Grup 1 hastalarında postoperatif direnaj daha fazla, yoğun bakım ve hastanede kalış sürelerinin de istatistiksel olarak anlamlı uzun olduğu tespit edildi (Tablo 4, $p<0.01)$.

Tablo 1. Grupların demografik verilerinin karşılaştırılması.

\begin{tabular}{|c|c|c|c|c|}
\hline & & Grup $1(n=43)$ & Grup 2 (n=207) & $\bullet p$ \\
\hline \multirow[t]{2}{*}{ Yaş } & $>60$ & 31 (\%72.1) & 89 (\%43.0) & $0.001 * *$ \\
\hline & $<60$ & $12(\% 27.9)$ & $118(\% 57.0)$ & \\
\hline \multirow[t]{2}{*}{ VKI } & 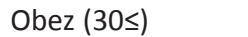 & $11(\% 26.2)$ & 64 (\%31.7) & ns \\
\hline & Aşırı kilolu (25-29) & $31(\% 73.8)$ & $138(\% 68.3)$ & \\
\hline \multirow[t]{2}{*}{ Cinsiyet } & Kadın & $11(\% 25.6)$ & 42 (\%20.3) & ns \\
\hline & Erkek & $32(\% 74.4)$ & 165 (\%79.7) & \\
\hline \multirow[t]{2}{*}{ HT } & Var & $38(\% 88.4)$ & 132 (\%63.8) & $0.002 * *$ \\
\hline & Yok & 5 (\%11.6) & 75 (\%36.2) & \\
\hline \multirow[t]{2}{*}{ Diyabet } & Var & $22(\% 51.2)$ & 78 (\%37.7) & ns \\
\hline & Yok & $21(\% 48.8)$ & $129(\% 62.3)$ & \\
\hline \multirow[t]{2}{*}{$\mathrm{KOAH}$} & Var & $3(\% 7.0)$ & 20 (\%9.7) & ns \\
\hline & Yok & $40(\% 93.0)$ & $187(\% 90.3)$ & \\
\hline
\end{tabular}

VKI: vücut kitle indeksi, HT: hipertansiyon, KOAH: kronik obstruktif akciğer hastalığı

- : Ki kare test, ** $p<0.01$ 
Tablo 2. Grupların preoperatif değişkenlerinin karşılaştırıması.

\begin{tabular}{|c|c|c|c|}
\hline & $\begin{array}{c}\text { Grup } 1 \\
n(\%)\end{array}$ & $\begin{array}{c}\text { Grup } 2 \\
\text { n (\%) }\end{array}$ & $\bullet p$ \\
\hline $\mathrm{PDH}$ & $1(\% 2.3)$ & 4 (\%1.9) & ns \\
\hline SVO & $6(\% 14.0)$ & $22(\% 10.6)$ & ns \\
\hline Statin & $18(\% 42.9)$ & $106(\% 51.2)$ & ns \\
\hline ACE inhibitörü & $27(\% 64.3)$ & $122(\% 58.9)$ & ns \\
\hline Ca kanal blokörü & $9(\% 21.4)$ & $16(\% 7.7)$ & $0.007 * *$ \\
\hline Preop MI & $26(\% 60.5)$ & 124 (\%59.9) & ns \\
\hline Sigara & $20(\% 46.5)$ & $96(\% 46.4)$ & ns \\
\hline Beta bloker & $23(\% 53.5)$ & $128(\% 61.8)$ & ns \\
\hline \multicolumn{4}{|l|}{$\mathrm{EF}(\%)$} \\
\hline$<50$ & $3(\% 7.0)$ & $23(\% 11.1)$ & ns \\
\hline$>50$ & $40(\% 93.0)$ & $184(\% 88.9)$ & \\
\hline †Kreatinin; (ort $\pm s d)$ & $0.96 \pm 0.21$ & $1.33 \pm 5.15$ & ns \\
\hline †+NYHA; ort \pm SD (medyan) & $3.38 \pm 0.89(4.0)$ & $3.39 \pm 0.65(3.0)$ & ns \\
\hline
\end{tabular}

PDH: periferik damar hastalığı, SVO: serebrovasküler olay, ACE: anjiotensin konverting enzim, MI: miyokard enfarktüsü, EF: ejeksiyon fraksiyonu, NYHA: Newyork kalp birliği sınıflaması

- Ki-kare test

t: student $t$ test, ++ : Mann Whitney $U$ test

$* * p<0.01$

\section{Tablo 3. Grupların intraoperatif değişkenlerinin değerlendirilmesi.}

\begin{tabular}{|c|c|c|c|}
\hline & $\begin{array}{c}\text { Grup } 1 \\
\mathrm{n}(\%)\end{array}$ & $\begin{array}{c}\text { Grup } 2 \\
\mathrm{n}(\%)\end{array}$ & $\bullet p$ \\
\hline \multicolumn{4}{|l|}{ Greft } \\
\hline 1 damar & 1 (\%2.3) & $13(\% 6.3)$ & ns \\
\hline 2 damar & $16(\% 37.2)$ & 66 (\%31.9) & \\
\hline 3 damar & $20(\% 46.5)$ & $80(\% 38.6)$ & \\
\hline 4 damar & 6 (\%14.0) & $43(\% 20.8)$ & \\
\hline 5 damar & $0(\% 0.0)$ & 5 (\%2.4) & \\
\hline PACE & $3(\% 7.0)$ & $9(\% 4.3)$ & ns \\
\hline IABP & 1 (\%2.3) & 3 (\%1.4) & ns \\
\hline \multirow[t]{2}{*}{ İnotrop } & $12(\% 27.9)$ & 40 (\%19.3) & ns \\
\hline & Ort $\pm S D$ (medyan) & Ort $\pm S D$ (medyan) & $t p$ \\
\hline Kros zamanı & $64.51 \pm 24.53$ & $63.91 \pm 27.30$ & ns \\
\hline Baypas süresi & $97.67 \pm 25.20$ & $96.58 \pm 38.22$ & ns \\
\hline IsI & $29.41 \pm 1.91$ & $29.80 \pm 2.10$ & ns \\
\hline
\end{tabular}

iABP: intraaortik balon pompası

- Ki-kare test

$t$ : student $t$ test, ++ : Mann Whitney $U$ test

${ }^{*} p<0.05$

CRP ölçümleri operasyondan itibaren yükselmeye başlayarak, en yüksek değerine postoperatif 2 günde ulaşmıştır. Benzer şekilde AF görülme oranı da en yüksek postoperatif 2. günde gözlenmiştir. Ancak bu dönemde, AF oranı ile CRP düzeyleri açısından gruplar karşılaştırıldığında, Grup 1'de CRP düzeyleri bir miktar daha yüksek bulunsa da, bu durum istatistik- sel olarak anlamlı bir farklııı yaratmamıştır (Şekil 1, $\mathrm{p}>0.05$ ).

Yoğun bakımdan servise çıkarılan hastaların $5^{\prime}$ i AF nedeniyle tekrar yoğun bakıma alınmıştır. AF saptanan 43 olgudan 37'sine amiadoron tedavisi uygulanmış, 1 olgu dışında sinüs ritmine dönüş sağlanmıştır 
Tablo 4. Grupların postoperatif değişkenlerinin değerlendirmesi.

\begin{tabular}{|c|c|c|c|c|}
\hline & & $\begin{array}{l}\text { Grup } 1 \\
(n=43)\end{array}$ & $\begin{array}{c}\text { Grup } 2 \\
(n=207)\end{array}$ & $\bullet p$ \\
\hline $\mathrm{Mg}^{++}$ & $\begin{array}{l}\leq 2(n=19) \\
>2(n=221)\end{array}$ & $\begin{array}{c}4(\% 9.3) \\
39(\% 90.7)\end{array}$ & $\begin{array}{c}15(\% 7.2) \\
192(\% 92.8)\end{array}$ & ns \\
\hline $\mathrm{K}+$ & $\begin{array}{l}\leq 3,5 \quad(n=19) \\
>3,5(n=221)\end{array}$ & $\begin{array}{c}5(\% 11.6) \\
38(\% 88.4)\end{array}$ & $\begin{array}{c}14(\% 6.8) \\
193(\% 93.2)\end{array}$ & ns \\
\hline ISI & $\begin{array}{l}\geq 38(n=8) \\
<38(n=242)\end{array}$ & $\begin{array}{c}0(\% 0.0) \\
43(\% 100.0)\end{array}$ & $\begin{array}{c}8(\% 3.9) \\
199(\% 96.1)\end{array}$ & $\begin{array}{c}\mathrm{ns} \\
0.023^{*} \\
\mathrm{~ns}\end{array}$ \\
\hline $\mathrm{Hb}$ & $\begin{array}{l}\leq 9 \operatorname{gr}(n=83) \\
>9 \operatorname{gr}(n=167)\end{array}$ & $\begin{array}{l}12(\% 27.9) \\
31(\% 72.1)\end{array}$ & $\begin{array}{c}71(\% 34.3) \\
136(\% 65.7)\end{array}$ & \\
\hline $\begin{array}{l}\text { Postop direnaj } \\
\text { Postop MI }\end{array}$ & & $\begin{array}{c}958.13 \pm 512.10 \\
0(\% 0.0)\end{array}$ & $\begin{array}{c}764.00 \pm 404.19 \\
2(\% 1.0)\end{array}$ & $\begin{array}{c}0.023^{*} \\
\mathrm{~ns}\end{array}$ \\
\hline & & Ort $\pm S D$ (medyan) & Ort $\pm S D$ (medyan) & $\begin{array}{l}\text { tp } \\
\text { ns }\end{array}$ \\
\hline Entübasyon süresi & & $20.46 \pm 27.26$ & $16.63 \pm 19.78$ & \\
\hline Yoğun bakımda kalış süresi & & $1.83 \pm 1.68(1.0)$ & $1.39 \pm 1.34(1.0)$ & $0.002 * *$ \\
\hline Hastanede kalış süresi & & $11.79 \pm 11.84(8.0)$ & $8.05 \pm 5.45(7.0)$ & $0.001 * *$ \\
\hline
\end{tabular}

Mg++: magnezyum, K+:potasyum, $\mathrm{Hb}$ : hemoglobin, MI: miyokard enfarktüsü

$\bullet:$ Ki kare test, + : Mann Whitney $U$ test

$* * p<0.01$

\section{Tablo 5. Değişkenlerin univariate ve multivariate analizi.}

\begin{tabular}{|c|c|c|c|c|}
\hline & \multicolumn{2}{|c|}{ Univariate } & \multicolumn{2}{|c|}{ Multivariate } \\
\hline & ODDS (\%95 Cl) & $p$ & ODDS (\%95 Cl) & $\mathbf{p}$ \\
\hline Yaş; >60 & 3,43 (1.66-7.04) & $0.001 * *$ & $0.32(0.15-0.74)$ & $0.007 * *$ \\
\hline BMI; Obez & $0,96(0.36-1.61)$ & 0.483 & & \\
\hline Cinsiyet; Kadın & $1,35(0.63-2.90)$ & 0.440 & & \\
\hline HT & $4,32(1.63-11.44)$ & $0.002 * *$ & 3.25 (1.17-8.90) & $0.024 *$ \\
\hline Diyabet & $1,73(0.89-3.35)$ & 0.101 & & \\
\hline $\mathrm{KOAH}$ & $0,70(0.19-2.47)$ & 0.579 & & \\
\hline PDH & $1,20(0.13-11.1)$ & 1.000 & & \\
\hline SVO & $1,36(0.51-3.59)$ & 0.529 & & \\
\hline Statin & 0,71 (0.36-139) & 0.324 & & \\
\hline ACE inhibitörü & $1,25(0.63-2.49)$ & 0.519 & & \\
\hline Ca kanal blokörü & 3,25 (1.32-7.97) & $0.007 * *$ & $2.79(1.04-7.32)$ & $0.041 *$ \\
\hline Preop MI & $1,02(0.52-2.00)$ & 0.945 & & \\
\hline Sigara & $1,00(0.52-1.94)$ & 0.987 & & \\
\hline Beta bloker & $0,71(0.36-1.37)$ & 0.308 & & \\
\hline IABP & $1,62(0.16-15.94)$ & 0.532 & & \\
\hline$E F<50$ & $0,60(0.17-2.09)$ & 0.419 & & \\
\hline İnotrop kullanımı & $1,61(0.76-3.42)$ & 0.207 & & \\
\hline $\mathrm{Mg}^{++}<2 \mathrm{mg}$ & $1,31(0.41-4.16)$ & 0.643 & & \\
\hline$K+<3,5$ & $1,81(0.62-5.33)$ & 0.273 & & \\
\hline $\mathrm{Hb}<9$ & $0,74(0.35-1.53)$ & 0.656 & & \\
\hline
\end{tabular}

HT: Hipertansiyon, KOAH: kronik obstruktif akciğer hastalığı, PDH: periferik damar hastalığı, SVO: serebrovasküler olay, ACE: anjiotensin konverting enzim, IABP: intraaortik balon pompası, EF: ejeksiyon fraksiyonu, $\mathrm{Mg}^{++}$: magnezyum, $\mathrm{K+}$ :potasyum, $\mathrm{Hb}$ : hemoglobin $*_{p<0,05, * * p<0,01}$ 


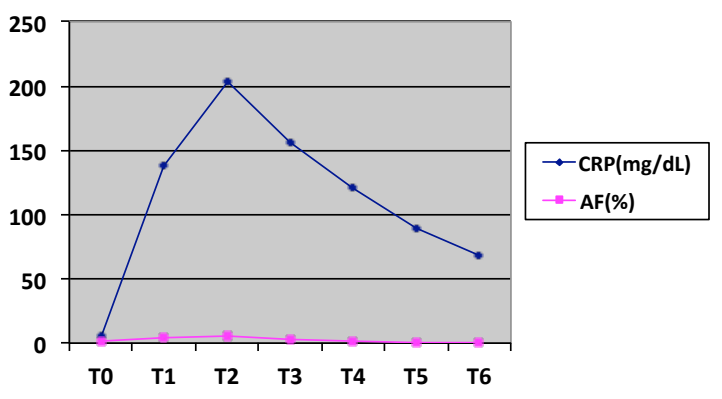

AF: atrial fibrilasyon, CRP: C reaktif protein

Şekil 1. Zamana göre AF gelişme ve CRP değişimleri.

(\%83). Üç hasta kendiliğinden, 3 hasta da $\mathrm{Mg}^{++}$tedavisi ile sinüs ritmine dönmüştür.

Univariate analizde, yaşın 60'ın üzerinde olması, preoperatif $\mathrm{HT}$ ve $\mathrm{Ca}^{++}$kanal blokeri kullanım öyküsü $\mathrm{AF}$ görülme riskini artırmaktadır $(\mathrm{p}<0.05)$. Multivariate analizde, AF gelişimine en fazla $H T^{\prime}$ 'nun etkisi olduğu, bunun riski 3,25 kat arttırdığı görülmüştür (OR:3,25; $\mathrm{Cl} \% 95: 1,04-7,32)$. Ca ${ }^{++}$kanal blokörü kullanımı riski 2,79 kat arttıırken (OR: 2,79; $\mathrm{Cl} \% 95: 1,09-7,32$ ), yaş parametresi modelde ileri düzeyde anlamlı bulunmasına rağmen, risk oranının düşük olduğu saptanmıştır (OR:0,32; Cl \%95: 0,15-0,74). Diğer parametrelerin anlamlı bulunmadığı saptanmıştır (Tablo 5 ).

\section{TARTIŞMA}

Cerrahi ve anestezideki gelişmeler ve myokard korumasındaki ilerlemelere rağmen KABG operasyonunu izleyen dönemde AF gibi aritmilerin sıklığında, önemli bir azalma sağlanamamıştır. KPB'ın neden olduğu sistemik enflamatuvar yanıtla birlikte, aortik kros klemplemeyi takiben gelişen reperfüzyon hasarı, hemodinamik bozulmayla karakterize postoperatif miyokardial hasara yol açar. Ortaya çıkan AF çoğunlukla geçici olup, kronik AF'ye dönüşme olasılığı azdır [13]. Çalışmamızda, bir hasta dışında uygulanan tedaviye cevap alınmıştır. Ancak AF varlığı, içinde bulunulan klinik tabloyu karmaşık hale getirip, olumsuz sonuçlara yol açma potansiyeli yüksektir. Bu aritmi KKY, serebrovasküler olaylar, renal disfonksiyon, enfeksiyon ve nörokognitif bozulma gibi komplikasyonların insidansını arttırır ${ }^{[14]}$. Postoperatif AF, genellikle operasyon sonrası 2. ve 3. günlerde gelişmektedir ${ }^{[15,16]}$. Yaptığımız çalışmanın sonucunda KABG operasyonu yapılan 250 hastanın 43'de AF saptanmış $(\% 17,2)$, en sık operasyon sonrası 2 . günde tespit edilmiş olup, literatür ile uyumludur.

KABG cerrahisi sonrası gelişen AF'nin prediktörleri arasında yaş, yapılan çalışmalar arasında tutarlı olan en önemli bağımsız risk faktörüdür ve yaştaki 10 yıllık artışın AF riskini \%70 arttırdığı tespit edilmiştir. Yaşla bağlantılı olarak kalpte fibrozis artışı ve atriyal dilatasyon kalpte yapısal değişiklikler oluşturur ${ }^{[17,18]}$. Çalışmamıza dahil edilen 250 hastanın 120'si 60 yaş üzerindedir ve AF saptanan 43 hastanın $31^{\prime} i$ bu yaş grubundadır. AF görülme oranı 60 yaş üzeri olgularda anlamlı düzeyde yüksek orandadır $(p<0.05)$.

Obezite, AF gelişmesi açısından önemli bir risk faktörü olabilir ${ }^{[19]}$. BMi, normalden fazla kilolu ve obez kategorilerine doğru ilerledikçe sol atrium boyutlarında kademeli bir artış olur. Atrium dilatasyonu kronik $A F^{\prime} l i$ olgularda oldukça sık görülen bir durumdur ve çoğu kez bu duruma kas liflerinde kopukluklar eşlik eder ${ }^{[20]}$. Bizim çalışmamızda ise obezite ile AF arasında anlamlı bir ilişki saptanmamıştır. Bunun nedeninin hasta popülasyonumuzun morbid obez hastalardan oluşmaması ve obez hasta sayısının az olmasından kaynaklandığını düşünüyoruz.

Bazı çalışmalarda erkeklerde postoperatif $A F^{\prime}$ nin daha sık gözlendiği belirtilmesine karşın, bazı çalışmalarda cinsiyetin belirleyici faktör olmadığı gösterilmiştir ${ }^{[21,22]}$. Bizim çalışmamızda ise takip edilen 250 hastanın 197'sini ve AF saptanan 43 olgunun 32'sini erkek hastalar oluşturmakla birlikte, AF ile cinsiyet arasında anlamlı bir ilişki saptanmamıştır.

AF ile ilişkili özgül kardiovasküler durumlar arasında, özellikle sol ventrikül hipertrofisiyle seyreden HT bulunmaktadır. $H T, A F$ 'nin ve tromboemboli gibi $A F$ komplikasyonlarının gelişmesi açısından en yaygın ve düzeltilme potansiyeli en yüksek, bağımsız risk faktö- 
rüdür. Patti ve ark. ${ }^{[23]}$, sistemik HT'nin AF için artmış risk faktörü olduğunu belirtmiştir. Bizim çalışmamızda da HT görülen olgularda AF oranı istatistiksel olarak yüksek olarak saptanmıştır $(p<0,01)$. Kan basıncı kontrolü $A F^{\prime}$ nin önlenmesinde elverişli bir strateji olabilir.

AF'de en etkili profilaktik tedavi beta-bloker verilmesidir. Beta blokerler aşırı katekolamin salınımından kaynaklanan akut veya kronik supraventriküler ve ventriküler aritmilerin önlenmesinde tercih edilmektedir ${ }^{[24]}$. Koroner cerrahi sonrasında daha önceden başlanmış olan beta blokerlerin kesilmemesi gerektiği, ancak önleyici amaçla tek başına verildiğinde AF önleyici etkisinin yeterli olmayacağını öne sürmüştür [25]. Statinlerin AF üzerindeki yararlı etkileri bir çok araştırmada belirtilmiştir. Retrospektif bir çalışmada, statinlerin kardioversiyon sonrası AF tekrarını azalttığı gösterilmiştir ${ }^{[26]}$. ARMYDA-3 çalışması, atorvastatin tedavisinin postoperatif AF sıklığını ve hastanede kalış süresini önemli ölçüde azalttığını göstermiştir [23]. AF gelişmesinde, RAAS'nin önemi konusundaki veriler giderek artmaktadır. Tek başına ya da diğer tedaviler ile birlikte RAAS inhibisyonu, atrial basınç ve duvar geriliminde azalma, sol atrium ve sol ventrikülde fibröz, dilatasyon ve hipertrofinin önlenmesi, nörohümoral aktivasyonun inhibisyonu, kan basıncını düşürme, KY'nin önlenmesi ya da azalması ve hipopotaseminin önlenmesi mekanizmalarıyla AF başlamasını ya da sürmesini önler ${ }^{[16,27]}$. Diltiazem, postoperatif $A F^{\prime}$ den korunmada önerilen, bazı çalışmalarda ise daha çok ventrikül hızını kontrol etmek için kullanılan bir ilaçtır ${ }^{[28-30]}$. Çalışmamızda preoperatif beta bloker, statin, ACE-i veya anjiotensin reseptör blokeri ve $\mathrm{Ca}++$ kanal blokeri kullanımı ile postoperatif AF gelişimi arasındaki ilişki incelendiğinde anlamlı bir ilişki saptanamamıştır. Ancak AF görülen olgularda, $\mathrm{Ca++}$ kanal blokeri kullanım oranları, AF olmayanlardan istatistiksel olarak anlamlı düzeyde yüksektir $(p<0,01)$. AF tedavisinde kullanılan amiodaron hem ventrikül hızının kontrolünde hem de sinüs ritminin tekrar sağlanmasında etkinliği olan bir ilaç olarak kabul görmüştür. Amiodaron, beta blokerler gibi membran stabilizan etkisiyle, başlangıçta i.v. infüzyon ve sonrasında oral idamesi ile AF tedavisinde en etkin tedavi protokolü olarak ön plana çıkmaktadır ${ }^{[16,31]}$. Kliniğimizde postoperatif AF tedavisinde rutin olarak amiodaron kullanılmakta olup, sonuçlarımıza göre AF saptanan 43 olgudan 37'sine amiodaron uygulanmış, 36 'nda sinüs ritmine dönüş sağlanmıştır.

Cerrahi sırasında AF gelişimine yol açan birçok faktör vardır, bunlar arasında adrenerjik tonus artışı, enflamasyon, perikardın hasarlanması, atriyum myokardının iskemisi, elektrolit anormallikleri (özellikle hipomagnezemi), inotropik ajan kullanılması, uzun krosklemp zamanı, bikaval kanülasyon sayılabilir [22]. Çalışmamızda hiçbir olguda bikaval kanülasyon tekniği kullanılmamıştır. Greft sayısı,aortik kros- kemp süresi, KPB süresi, inotrop ve İAB kullanımı ile postoperatif $\mathrm{AF}$ arasında bir ilişki saptanmamıştır.

KPB, rahat ve güvenli anastomoz sağlamasına rağmen sistemik bir enflamatuvar yanıt ortaya çıkarmaktadır. Gelişen sistemik inflamatuvar yanıtta postoperatif organ disfonksiyonuna yol açarak mortalite ve morbiditeyi arttırmaktadır. CRP her türlü enflamatuar stimulusa yanıt olarak hızla karaciğerden salınan bir proteindir ve artmış koroner olay riski ile ilişkili olduğu gösterilmiştir. ARMYDA-3 çalışmasında postoperatif tepe CRP seviyelerinin AF bulunan hastalarda yüksek olduğu saptanmış ve çok değişkenli analizde medyan değer üzerindeki CRP değerlerinin artmış risk ile ilişkili olduğu gösterilmiştir ${ }^{[23]}$. Çalışmamızda en yüksek CRP değerlerine postoperatif 2. gün rastlanmış olup, en çok $A F^{\prime}$ de aynı gün tespit edilmiştir. AF görülen olgularda CRP bir miktar daha yüksek olarak saptansa da AF ile CRP arasında istatiksel olarak bir ilişki saptanmamıştır.

Postoperatif AF genellikle ölümcül değildir ancak ciddi morbiditeye, uzamış hastanede yatış süresine ve maliyete neden olur ${ }^{[4,5]}$. Çalışmamızda yoğun bakımda ve hastanede kalış süreleri AF görülen olgularda istatistiksel olarak anlamlı düzeyde uzun olarak saptanmıştır $(p<0,01)$. Yoğun bakımdan servise çıkarılan hastaların $5^{\prime} \mathrm{i}, \mathrm{AF}$ nedeniyle tekrar yoğun bakı- 
ma alınmıştır. Kanama miktarı AF görülen olgularda istatistiksel olarak anlamlı düzeyde yüksek olarak saptanmıştır $(p<0,05)$. Postoperatif direnaj miktarının artışı, epikardiyal irritasyon nedeniyle, hemorajinin kitle etkisi nedeniyle atriyal basıya neden olması, bölgesel inflamasyon artışına, trombosit adezyon ve agregasyonuna neden olarak postoperatif AF gelişimi için bağımsız bir risk faktörüdürr ${ }^{[32]}$.

Çalışmamızın önemli bir sınırlaması AF belirlenmesinde holter monitörünün kullanılamamış olmasıdır. Yoğun bakımda sürekli monitör, serviste ise şikayet üzerine veya belli aralıklarla çekilen 12 derivasyonlu EKG ile AF değerlendirildi. Bu durumda kısa süreli , asemptomatik, kendi kendine düzelen paroksismal AF atakları değerlendirilememiş olabilir.

Sonuç olarak, AF koroner arter cerrahisi sonrası en sık görülen aritmidir. Cerrahi ve anestezideki gelişmeler ile myokard korumasındaki ilerlemelere rağmen, bu aritmilerin sıklığında önemli bir azalma sağlanamamıştır. AF postoperatif morbiditeyi arttırken, hastanede kalış süresini ve tedavi masraflarını da arttırır. Cerrahi öncesinde olguların risk faktörleri yönünden değerlendirilmesi AF gelişmesini önleyici tedbirlerin alınabilmesine olanak sağlar.

\section{KAYNAKLAR}

1. Adalet K. Atriyal fibrilasyonun güncel farmakolojik tedevasi. Türk kardiyol Dern Arş 2002;30:104-18 .

2. Marso SP, Griffin BP, Topol EJ. Manual of cardiovascular medicine. Phiadephia: Lippincott Williams \& Wilkins;2000.

3. Mashat AA, Subki AH, Bakhaider MA. Atrial fibrillation: risk factors and comorbidities in a tertiary center in Jeddah, Saudi Arabia. Int J Gen Med. 2019 Jan 11;12:7177.

https://doi.org/10.2147/IJGM.S188524

4. Creswell LL, Damiano RJ. Postoperative atrial fibrillation: an old problem crying for new solutions. J Thorac Cardiovasc Surg. 2001; 121: 638 - 641. https://doi.org/10.1067/mtc.2001.114347

5. Steinberg BA, Zhao $Y$, He $X$, Hernandez AF, Fullerton DA, Thomas $K$, et al. Management of postoperative atrial fibrillation and subsequent outcomes in contemporary patients undergoing cardiac surgery: insights from the Society of Thoracic Surgeons CAPS-Care Atrial Fibrillation Registry. Clin Cardiol. 2014;37:7-13. https://doi.org/10.1002/clc.22230

6. Tinica G, Mocanu V, Zugun-Eloae F and Butcovan D. Clinical and histological predictive risk factors of atrial fibrillation in patients undergoing open-heart surgery Exp Ther Med. 2015 Dec;10(6):2299-304. https://doi.org/10.3892/etm.2015.2790

7. Engelman MD, Svendsen JH. Inflammation in the genesis and perpetuation of atrial fibrillation. Eur Heart J 2005;26:2083-92. https://doi.org/10.1093/eurheartj/ehi350

8. Boos CJ, Anderson RA, Lip GY. Is atrial fibrillation an inflammatory disorder? Eur Heart J 2006;27:136-49. https://doi.org/10.1093/eurheartj/ehi645

9. Ehrlich JR, Hohnloser SH, Nattel S. Role of angiotensin system and effects of its inhibition in atrial fibrillation: clinical and experimental evidence. Eur Heart J 2006;27:512-8. https://doi.org/10.1093/eurheartj/ehi668

10. Brasier AR, Recinos A, Eledrisi MS. Vascular inflammation and the renin angiotensin system. Arterioscler Thromb Vasc Biol 2002;22:1257-66. https://doi.org/10.1161/01.ATV.0000021412.56621.A2

11. Chung MK, Martin DO, Sprecher D, Wazni O, Kanderian A, Canes CA, Bauer JA, et al. C- reactive protein elevation in patientd with atrial arythmias; inflammatory mechanisms and persistance of atrial fibrillation. Circulation 2001;104:2886-91. https://doi.org/10.1161/hc4901.101760

12. Manfrini O, Cenko E, Ricci B, Bugiardini R. Post cardiovascular surgery atrial fibrillation. Biomarkers Determining Prognosis. Curr Med Chem. 2019;26(5): 916-24. https://doi.org/10.2174/0929867324666170727104930

13. Chung MK. Cardiac surgery: potoperative arrhythmias. Crit Care Med 2000;28(10 Suppl): N136-44. https://doi.org/10.1097/00003246-200010001-00005

14. Houge CW Jr, Creswell LL, Gutterman DD, Fleisher LA; American College of Chest Physicians. Epidemiology, mechanisms and risks: American College of Chest Physicians guidelines fort he prevention andmanagement of postoperative atrial fibrillation after cardiac surgery. Chest. 2005;128:9-16. https://doi.org/10.1378/chest.128.2_suppl.9S

15. Farouk Musa A, Quan CZ, Xin LZ. A retrospective study on atrial fibrillation after coronary artery bypass grafting surgery at The National Heart Institute, Kuala Lumpur. Version 2. F1000Res. 2018 Feb 8;7:164. https://doi.org/10.12688/f1000research.13244.2

16. Hogue CW Jr, Hyder ML,. Atrial fibrillation after cardiac operation: Risks, mechanism and treatment. Ann Thorac Surg 2000;69:300-6. 
https://doi.org/10.1016/S0003-4975(99)01267-9

17. Maisel WH, Rawn JD, Stevenson WG. Atrial fibrillation after cardiac surgery. Ann Intern Med. 2001;135:106173.

https://doi.org/10.7326/0003-4819-135-12200112180-00010

18. Bessissow A, Khan J, Devereaux PJ, Alvarez-Garcia J, Alonso-Coello P. Postoperative atrial fibrillation in noncardiac and cardiac surgery: an overview. J Thromb Haemost. 2015 Jun;13 Suppl 1:S304-12. https://doi.org/10.1111/jth.12974

19. Frost L, Hune LJ, Vestergaard P. Overweight and obesity as risk factors for atrial fibrilation or flutter: the Danish Diet, Cancer, and Health Study. Am J Med. 2005;118:48995.

20. Ekim H, Kutay V, Demirbağ R, Turan E, Hazar A, Karadağ M. Koroner arter cerrahisi sonrası atrial fibrilasyon gelişiminde rol oynayan faktörler. Van Tıp Dergisi: 11 (2):43-47, 2004.

21. Funk M, Richards SB, Desjardins J, Bebon C. Incidince, timing, symptoms, and risk factors for atrial fibrillation after cardiac surgery. Am J Crit Care 2003;12:424-45. https://doi.org/10.4037/ajcc2003.12.5.424

22. Filardo G, Ailawadi G, Pollock BD. Postoperative atrial fibrillation: Sex-specific characteristics and effect on survival. J Thorac Cardiovasc Surg. 2020 Apr;159(4): 1419-25. https://doi.org/10.1016/j.jtcvs.2019.04.097

23. Giuseppe Patti, Massimo Chello, Dario candura, et al. Randomized Trial of Atorvastatin for Reduction of Postoperative Atrial Fibrillation in Patients Undergoing Cardiac Surgery (ARMYDA-3). Circulation. 2006;114: 1455-61. https://doi.org/10.1161/CIRCULATIONAHA.106.621763

24. Crystal E, Connolly SJ, Sleik K, et al. Interventions on prevention of postoperative atrial fibrillation in patients undergoing heart surgery: a meta-analysis.
Circulation 2002;106:75-80.

https://doi.org/10.1161/01.CIR.0000021113.44111.3E

25. Gudbjartsson T, Helgadottir S, Sigurdsson MI. Newonset postoperative atrial fibrillation after heart surgery. Acta Anaesthesiol Scand. 2020 Feb;64(2):14555. https://doi.org/10.1111/aas.13507

26. Siu CW, Lau CP, Tse HF. Prevention of atrial fibrillation a diversion. Am J Cardiol. 2003;92:1343-45. https://doi.org/10.1016/j.amjcard.2003.08.023

27. Nattel $S$, New ideas about atrial fibrillation 50 years on. Nature 2002;415:219-26. https://doi.org/10.1038/415219a

28. Healey JS, Baranchuk A, Crystal E, et al. Prevention of atrial fibrillation with anjiotensin converting enzyme inhibitors and anjiotensin receptor blockers: a metaanalysis. J Am Coll Cardiol. 2005;45:1832-9. https://doi.org/10.1016/j.jacc.2004.11.070

29. Weymann A, Popov AF, Sabashnikov A, et al. Baseline and postoperative levels of $\mathrm{C}$-reactive protein and interleukins as inflammatory predictors of atrial fibrillation following cardiac surgery: a systematic review and meta-analysis. Kardiol Pol. 2018;76(2):440-51. https://doi.org/10.5603/KP.a2017.0242

30. Sony Jacob , Omaima A Ali, Victoria Pidlaoan, Apurva O Badheka, Nicholas Z Kerin. Pharmacotherapy of Atrial Fibrillation: A Pathophysiological Perspective and Review. Am J Ther 2011 May;18(3):241-60 https://doi.org/10.1097/MJT.0b013e3181eea7c5

31. Baeza-Herrera LA, Rojas-Velasco G, Márquez-Murillo MF. Atrial fibrillation in cardiac surgery. Arch Cardiol Mex. 2019;89(4):348-59. https://doi.org/10.24875/ACME.M20000068

32. Atılgan K, Demirdaş E, Günay C. Koroner arter cerrahisi sonrası görülen atriyal fibrilasyon gelişimine etki eden faktörler Bozok Tıp Derg. 2017;7(4):29-35. 